Int. J. Morphol.,

36(1):362-366, 2018.

\title{
Computed Tomography-Guided Bone Block Harvesting From the Mandibular Ramus
}

\author{
Toma de Bloque Óseo de Rama Mandibular Guiada por Tomografía Computadorizada
}

\author{
Marcelo Parra'; Jaime Jara²; Pablo Navarro³ ${ }^{3}$ Bélgica Vásquez ${ }^{4}$ \& Sergio Olate ${ }^{5,6}$
}

PARRA, M.; JARA, J.; NAVARRO, P.; VÁSQUEZ, B. \& OLATE, S. Computed tomography-guided bone block harvesting from the mandibular ramus. Int. J. Morphol., 36(1):362-366, 2018.

SUMMARY: The aim of this study was to ascertain the distance from the mandibular canal to the lateral, medial and upper zones of the mandibular ramus in order to identify safety margins that reduce the risk of nerve injuries in the process of removing a bone graft. A descriptive study was conducted, analyzing bilaterally 20 CBCT exams from different patients, taking measurements at 4 points in the central, lateral and medial areas of the corresponding mandibular ramus, which was located at a distance of $5 \mathrm{~mm}$ between each line, starting at the distal point of the second molar. Forty hemimandibles were included in this study, estimating a vertical distance for the 4 points of analysis, from between 16 and $17 \mathrm{~mm}$, a distance laterally of $5 \mathrm{~mm}$ approximately and medially approximately from 3 to 3.9 $\mathrm{mm}$; the lateral zone was significantly larger than the medial zone. It is estimated that the maximum achievement of a bone block from the area posterior to the second molar must be $13 \mathrm{~mm}$ deep and $3 \mathrm{~mm}$ laterally to minimize the risks of injuries to the inferior alveolar neurovascular bundle.

KEY WORDS: Mandibular ramus; Bone graft; Donor site.

\section{INTRODUCTION}

Bone reconstruction, before or during implant installation, is a routine technique in modern dentoalveolar rehabilitation. Classically, reconstruction with autogenous bone has been used with a high success rate (Sakkas et al., 2017), although the use of other materials has shown favorable results in some cases (Deluiz et al., 2017).

The discussion on the effectiveness and efficiency of one or the other type of material has not been completely resolved, since many studies have methodologies that cannot be compared; there is clarity, however, that the increase in width of the alveolar process is positively related to the use of autogenous bone graft blocks, as these are stabilized with screws using generally compressive techniques (Sakkas et al., 2017).

One of the important disadvantages in obtaining intraoral bone grafts is the need to operate on a second intraoral site and thus generate greater morbidity in the patient, creating problems associated with changes in the regional morphology, secondary infections or neurosensory alterations (Restoy-Lozano et al., 2015). The most used intraoral sites for obtaining bone graft blocks are the mandibular symphysis region and the mandibular ramus (Reininger et al., 2016), although others such as the zygomatic bone region and the maxillary or mandibular torus have also been reported (Hassan et al., 2015; Sakkas et al., 2016).

Using the symphysis as a donor site has been strongly linked to neurosensory alterations like paresthesia of the lower anterior dentogingival region (Reininger et al.), lower lip ptosis (Altiparmak et al., 2017) and gum recession (Altiparmak). Recently, some studies have demonstrated the presence of a limited cortical bone structure and safety areas that limit a broad removal of bone from the area (Altug et al., 2016; Velásquez et al., 2017).

\footnotetext{
${ }^{1} \mathrm{PhD}$ Program in Morphological Sciences, Universidad de La Frontera, Temuco, Chile.

${ }^{2}$ Dental School, Universidad de La Frontera, Temuco, Chile.

${ }^{3}$ Center for Research in Dental Sciences, Universidad de La Frontera, Temuco, Chile.

${ }^{4}$ Universidad de Tarapaca, Arica, Chile.

${ }^{5}$ Division of Oral, Facial \& Maxilofacial Surgery, Universidad de La Frontera, Temuco, Chile.

${ }^{6}$ Center of Excellence in Morphological and Surgical Sciences, Universidad de La Frontera, Temuco, Chile.
} 
On the other hand, the mandibular ramus has been used with low indices of neurosensory alterations (Reininger et al.); this anatomical zone does not generally present any significant morphological consequences and is not associated with dental alterations when the bone is removed. The few neurosensory alterations that may occur can be limited by knowing precisely the position of the inferior alveolar nerve (Kawashima et al., 2016). While cone beam computed tomography has enabled important advances in this analysis, studies in this area are still limited.

The aim of this study was to ascertain the distance from the mandibular canal to the lateral and upper areas in order to identify safety margins that reduce the risk of nerve injuries in the bone removal process.

\section{MATERIAL AND METHOD}

A descriptive study was conducted using cone beam computed tomography (CBCT) to characterize the mandibular ramus area in adult patients who consulted in the Oral and Maxillofacial Surgery Unit of the Universidad de La Frontera, Temuco, Chile, measuring the distances between the mandibular canal and the alveolar, buccal and lingual margins. Convenience sampling was used, including 20 CBCT examinations labeled from 1 to 20 to protect patient privacy. The subjects in the sample signed an informed consent for the study.

Inclusion and exclusion criteria. The inclusion criteria were: i) initial consultation at the Oral and Maxillofacial Surgery Service in the Universidad de La Frontera, ii) subjects of either gender aged between 18 and 60 years, iii) presence of permanent second molar, iv) presence of CBCT images for diagnosis and surgical planning according to each

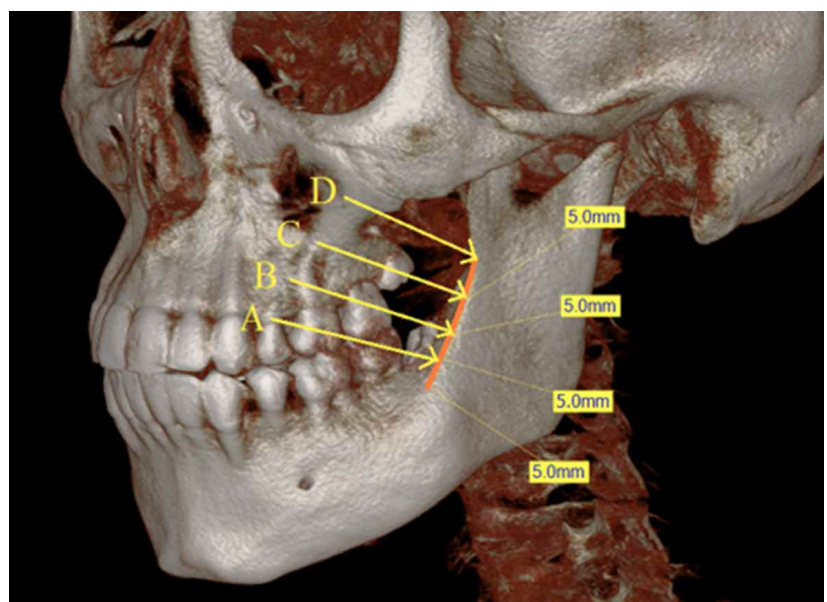

Fig. 1. Landmarks used to perform the measurements. patient's needs. Cases were excluded that presented periodontal disease involving the loss of alveolar bone in the posterior mandibular sector, the presence of facial malformations, facial tumors or facial trauma or the presence of bone metabolism pathology.

CBCT analysis. The measurements were taken by two calibrated researchers (MP and JJ) with the EZ3D2009 software (E-WOO Technology Co., Ltd., Korea). On each CBCT 4 points from the central, lateral and medial zones of the corresponding mandibular branch were assessed bilaterally, located at a distance of $5 \mathrm{~mm}$ between each line up to 20 $\mathrm{mm}$. The measurement points were: point A: $5 \mathrm{~mm}$ distally from the second molar; point B: $5 \mathrm{~mm}$ distally from point A; point C: $5 \mathrm{~mm}$ distally from point $\mathrm{B}$ and point $\mathrm{D}: 5 \mathrm{~mm}$ distally from point $\mathrm{C}$ (Fig. 1). Then, on the coronal view of the CBCT three measurements at each of these four points were taken as follows: D1: distance laterally to the mandibular canal and the superior alveolar ridge; D2: distance between the outer edge of the mandibular canal and the buccal bone margin, and D3: distance between the outer edge of the mandibular canal and the lingual bone margin of the mandible (Fig. 2).

Data analysis. The data were recorded on a Microsoft Excel ${ }^{\circledR}$ spreadsheet. For the data analysis the statistical program SPSS Statistics for Windows (version 23.0, IBM) was used and a descriptive analysis was done of the data as well as the Shapiro-Wilk test of normality; Levene's test for homogeneity of variances was used and the t-test for independent samples with a value of $\mathrm{p}<0.05$ to obtain statistical significance. Together $95 \%$ confidence intervals of reliability were determined.

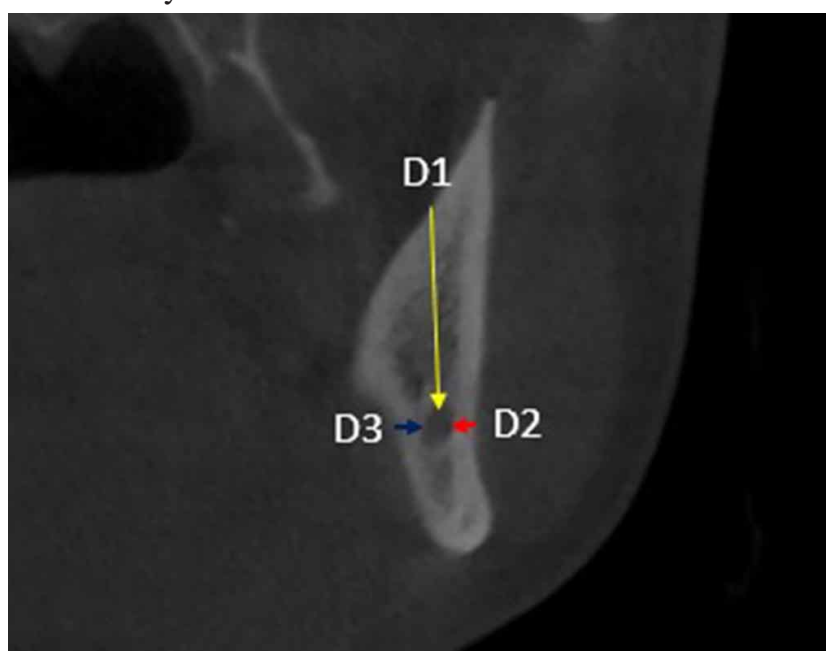

Fig. 2. Measurements taken at each area: D1: distance between the mandibular canal and the upper bone ridge, D2: distance between the outer edge of the mandibular canal and the buccal bone margin and D3: distance between the outer edge of the mandibular canal and the lingual bone margin of the mandible. 


\section{RESULTS}

Forty hemimandibles were included in this study, 16 $(40 \%)$ of which were male and $24(60 \%)$ female, with an age range from 18 to 60 years. The measurements were taken by two operators, obtaining an intraclass correlation coefficient of 0.85 , confirming the viability of the

Tables I and II show the measurements obtained in the study on the right and left hemimandibles. The means of the distances between the superior alveolar ridge (D1), the buccal margin (D2), the lingual margin (D3) and the mandibular canal at each of the points showed regularity with a close standard deviation among them. It was determined that the D3 zone was the smallest. Comparing the right and left rami, no significant differences were observed $(\mathrm{p}=0.102)$.

The vertical distance for the 4 points of analysis was on average between 16 and $17 \mathrm{~mm}$; the distance laterally was $5 \mathrm{~mm}$ approximately and the distance medially was from 3 to $3.9 \mathrm{~mm}$.

Comparing the relation between the medial (D3) and lateral (D2) distances, it was noted that D2 was consistently greater than D3 in all the observations, and with the t-test for independent samples significant differences were observed in both measurements in all mandibular zones, determining that the lateral region of the mandibular ramus is greater than the inner region. measurements.

\section{DISCUSSION}

As a donor site to extract bone graft blocks, the mandibular ramus is reliable and versatile with a low rate of complications (Reininger et al.), which means it can be managed with limited morbidity. The results of this study show that, respecting certain limits, it is possible to obtain an autogenous bone block that allows a small reconstruction of the alveolar process (Sakkas et al., 2017). Safety margins used in the osteotomy must be included to reduce the risk of neurosensory injuries that are the main alterations in bone graft removal in this sector (Lee \& Kim, 2015).

One relevant aspect when planning a bone reconstruction using an autogenous graft is to be objective about the distances between the bone margins and the noble anatomical structures that can suffer irreversible changes (Fujita \& Shintani, 2015). When using the mandibular ramus as a donor site, the position and location of the inferior alveolar nerve must be defined (Nagadia et al., 2011) because the main risk in the use of the mandibular ramus as a donor site is neurosensory injuries (Lee \& Kim).

In terms of morphology of the zone, distally to the second molar, Fujita \& Shintani, using CBCT examinations, took vertical measurements at four different points between the mandibular canal and the alveolar ridge. In the area 15 $\mathrm{mm}$ posterior to the lower second molar, they estimated an average distance of $15.16 \pm 3.32 \mathrm{~mm}$; in the same zone our results show vertical distances of $17.3 \pm 3.3 \mathrm{~mm}$ in the left ramus and $16.1 \pm 3.4 \mathrm{~mm}$ in the right ramus, demonstrating a certain closeness in the results.

Table I. Distances obtained from the right mandibular ramus measurement in 20 subjects using CBCT. Height, lateral and medial measurement from the NAI will be realized.

\begin{tabular}{ccccc}
\hline Area of analysis & D1 $(\mathrm{mm})$ & D2 $(\mathrm{mm})$ & D3 $(\mathrm{mm})$ & $p$ value (D2 vs. D3) \\
\hline A & $17,1 \pm 3,7$ & $5,4 \pm 1,7$ & $3,6 \pm 0,9$ & $0,000^{*}$ \\
B & $17,4 \pm 3,8$ & $5,1 \pm 1,5$ & $3,9 \pm 1,5$ & $0,019^{*}$ \\
C & $17,3 \pm 3,3$ & $4,9 \pm 1,5$ & $3,9 \pm 1,4$ & $0,031^{*}$ \\
D & $17,1 \pm 4,5$ & $5,0 \pm 1,4$ & $3,8 \pm 1,3$ & $0,009^{*}$ \\
\hline
\end{tabular}

D1: distance laterally to the mandibular canal and the superior alveolar ridge; D2: distance between the outer edge of the mandibular canal and the buccal bone margin, and D3: distance between the outer edge of the mandibular canal and the lingual bone margin of the mandible. *Statistical significance.

Table II. Averages of measurements obtained on 40 hemimandibles in the posterior region of the mandible, left mandibular ramus.

\begin{tabular}{cllcc}
\hline Area of analysis & D1 $(\mathrm{mm})$ & D2 $(\mathrm{mm})$ & D3 $(\mathrm{mm})$ & p value (D vs. D3) \\
\hline A & $16,8 \pm 3,6$ & $5,6 \pm 1,5$ & $3,1 \pm 1,1$ & $0,000^{*}$ \\
B & $16,3 \pm 3,6$ & $5,2 \pm 1,5$ & $3,5 \pm 1,8$ & $0,003^{*}$ \\
C & $16,1 \pm 3,4$ & $5,2 \pm 1,1$ & $3,4 \pm 1,3$ & $0,000^{*}$ \\
D & $16,1 \pm 3,9$ & $5,1 \pm 1,3$ & $3,0 \pm 0,9$ & $0,000^{*}$ \\
\hline
\end{tabular}

D1: distance laterally to the mandibular canal and the superior alveolar ridge; D2: distance between the outer edge of the mandibular canal and the buccal bone margin, and D3: distance between the outer edge of the mandibular canal and the lingual bone margin of the mandible. *Statistical significance
Similarly, the distance laterally was evaluated by Nagadia et al., who, in a study done with tomography images, measured the distances between the buccal bone margin and the mandibular canal, indicating that at the level of the lower first molar, this distance varies between 3.71 and $6.91 \mathrm{~mm}$ with an average of $5.44 \mathrm{~mm}$. For their part, Kawashima et al. estimated in male patients a distance between the buccal bone margin and the mandibular canal of $4.94 \pm 1.57 \mathrm{~mm}$ in the right ramus and $5.70 \pm 1.54$ in the left ramus, whereas in women, these values were $5.91 \pm 1.60$ $\mathrm{mm}$ and $6.06 \pm 1.36 \mathrm{~mm}$ in the right and left rami, respectively. Our results showed values of not less than $4 \mathrm{~mm}$, which also close to our results. 
Based on these orientations, it is possible to work with safety margins in osteotomies that limit the risks of neurosensory alterations; Lee \& Kim recommend a maximum osteotomy depth of $14 \mathrm{~mm}$ when performing the surgical approach to obtain a bone graft block from the mandibular ramus. If we consider at least a $1 \mathrm{~mm}$ safety margin in this zone, based on our results, the maximum vertical extension must be 13 mm. Likewise, Leong et al. (2010), realizing a study on 34 corpses, indicated that it is not advisable to go deeper than $3 \mathrm{~mm}$ from the buccal bone margin in the direction of the mandibular canal. In our results, $4 \mathrm{~mm}$ was the minimum distance, so that $3 \mathrm{~mm}$ can be the safety margin in the lateral osteotomy.

With respect to the average volume of a bone block to extract from the mandibular ramus, Verdugo et al. (2014) estimated an average volume of $0.82 \pm 0.51 \mathrm{~cm} 3$, with a range between 0.42 and $1.31 \mathrm{~cm} 3$. Meanwhile, De Stavola et al. (2017) estimated an average bone volume of $0.8 \pm$ $0.51 \mathrm{~cm} 3$. Our results indicate that the maximum block obtained from the zone posterior to the second molar must be $13 \mathrm{~mm}$ in depth and $3 \mathrm{~mm}$ laterally, considering an anteroposterior extension of $20 \mathrm{~mm}$, a block with a volume of $0.78 \mathrm{~cm} 3$ can be obtained, which is consistent with what has been reported in the literature; however, this amount can limit the yield for some reconstructions of greater volume (Olate et al., 2015).

Bone graft blocks from the mandibular ramus have been widely used in small bone reconstructions prior to the installation of dental implants (Voss et al., 2016), which have shown high success rates of implants installed in grafted sites (Clementini et al., 2011). Peñarrocha-Oltra et al. (2014), in a study conducted on 37 patients, showed a $91 \%$ success rate of dental implants in sites augmented with bone from the mandibular ramus. Voss et al. indicated a $98 \%$ success rate, and there have also been reports of $100 \%$ success (Streckbein et al., 2014; Restoy-Lozano et al.; Sakkas et al., 2016).

Therefore, an increase of $3 \mathrm{~mm}$ in width can be considered as viable in horizontal increases using a bone graft in a block extracted from the mandibular ramus, which may be a limitation in more demanding cases.

PARRA, M.; JARA, J.; NAVARRO, P.; VÁSQUEZ, B. \& OLATE, S. Toma de bloque óseo de rama mandibular guiada por tomografía computadorizada. Int. J. Morphol., 36(1):362-366, 2018.

RESUMEN: El objetivo de esta investigación fue conocer la distancia que existe desde el canal mandibular a la zona lateral, medial y a la zona superior de la rama mandibular a fin de identificar márgenes de seguridad que minimicen el riesgo de lesiones nerviosas en el proceso de retiro de un injerto óseo. Se realizó un estudio descriptivo, analizando bilateralmente 20 exámenes CBCT de pacientes distintos, realizando mediciones en 4 puntos de la zona central, lateral y medial de la rama mandibular correspondiente, los cuales fueron ubicados con distancia de $5 \mathrm{~mm}$ entre cada línea, iniciando en el punto distal del segundo molar. Cuarenta hemimandíbulas fueron incluidas en esta investigación, estimando una distancia vertical, para los 4 puntos de análisis, de entre 16 y $17 \mathrm{~mm}$, una distancia hacia lateral de $5 \mathrm{~mm}$ aproximadamente y hacia medial aproximadamente de 3 a $3,9 \mathrm{~mm}$; la zona lateral fue significativamente mas grande que la zona medial. Se estima, que la obtención máxima de un bloque óseo desde la zona posterior al segundo molar debe ser con $13 \mathrm{~mm}$ de profundidad y 3 $\mathrm{mm}$ desde lateral para minimizar los riesgos de lesiones al paquete neurovascular alveolar inferior.

PALABRAS CLAVE: Rama mandibular; Injerto óseo; Sitio donante.

\section{REFERENCES}

Altiparmak, N.; Akdeniz, B. S.; Akdeniz, S. S. \& Uçkan, S. Changes in the lower lip soft tissue after bone graft harvesting from the mandibular symphysis. Int. J. Oral. Maxillofac. Surg., 46(1):129-33, 2017.

Altug, H. A.; Coskun, A. T.; Kamburoglu, K.; Zerener, T.; Gulen, O.; Sencimen, M. \& Ozkan, A. Volumetric evaluation of safe zone for bone harvesting from symphysis region by using cone beam computed tomography. Implant Dent., 25(6):758-61, 2016.

Clementini, M.; Morlupi, A.; Agrestini, C. \& Ottria, L. Success rate of dental implants inserted in autologous bone graft regenerated areas: a systematic review. Oral Implantol. (Rome), 4(3-4):3-10, 2011.

De Stavola, L.; Fincato, A.; Bressan, E. \& Gobbato, L. Results of computerguided bone block harvesting from the mandible: A case series. Int. J. Periodontics Restorative Dent., 37(1):e111-9, 2017.

Deluiz, D.; Santos Oliveira, L.; Ramôa Pires, F.; Reiner, T.; Armada, L.; Nunes, M. A. \& Muniz Barretto Tinoco, E. Incorporation and remodeling of bone block allografts in the maxillary reconstruction: A randomized clinical trial. Clin. Implant Dent. Relat. Res., 19(1):18094, 2017.

Fujita, A. \& Shintani, S. Computed tomographic analysis of the mandibular body and ramus in japanese patients: Relevance to bone harvesting from the mandibular ramus. Implant Dent., 24(4):402-6, 2015.

Hassan, K. S.; Al-Agal, A.; Abdel-Hady, A. I.; Swelam, W. M. \& Elgazzar, R. F. Mandibular tori as bone grafts: an alternative treatment for periodontal osseous defects - clinical, radiographic and histologic morphology evaluation. J. Contemp. Dent. Pract., 16(3):192-200, 2015.

Kawashima, Y.; Sakai, O.; Shosho, D.; Kaneda, T. \& Gohel, A. Proximity of the mandibular canal to teeth and cortical bone. J. Endod., 42(2):2214, 2016.

Lee, H. G. \& Kim, Y. D. Volumetric stability of autogenous bone graft with mandibular body bone: cone-beam computed tomography and threedimensional reconstruction analysis. J. Korean Assoc. Oral Maxillofac. Surg., 41(5):232-9, 2015.

Leong, D. J.; Li, J.; Moreno, I. \& Wang, H. L. Distance between external cortical bone and mandibular canal for harvesting ramus graft: a human cadaver study. J. Periodontol., 81(2):239-43, 2010.

Nagadia, R.; Tay, A. B.; Chan, L. L. \& Chan, E. S. The spatial location of the mandibular canal in Chinese: a CT study. Int. J. Oral Maxillofac. Surg., 40(12):1401-5, 2011. 
Olate, S.; Marín, A.; Oporto, G.; Farias, D. \& Cantín, M. Alveolar ridge splitting for implant installation in atrophic sites. Analysis of a case series. Int. J. Odontostomatol., 9(2):249-54, 2015.

Peñarrocha-Oltra, D.; Aloy-Prósper, A.; Cervera-Ballester, J.; PeñarrochaDiago, M.; Canullo, L. \& Peñarrocha-Diago, M. Implant treatment in atrophic posterior mandibles: vertical regeneration with block bone grafts versus implants with $5.5-\mathrm{mm}$ intrabony length. Int. J. Oral Maxillofac. Implants, 29(3):659-66, 2014.

Reininger, D.; Cobo-Vázquez, C.; Monteserín-Matesanz, M. \& LópezQuiles, J. Complications in the use of the mandibular body, ramus and symphysis as donor sites in bone graft surgery. A systematic review. Med. Oral Patol. Oral Cir. Bucal, 21(2):e241-9, 2016.

Restoy-Lozano, A.; Dominguez-Mompell, J. L.; Infante-Cossio, P.; LaraChao, J. \& Lopez-Pizarro V. Calvarial bone grafting for three-dimensional reconstruction of severe maxillary defects: A case series. Int. J. Oral Maxillofac. Implants, 30(4):880-90, 2015.

Sakkas, A.; Schramm, A.; Karsten, W.; Gellrich, N. C. \& Wilde, F. A clinical study of the outcomes and complications associated with zygomatic buttress block bone graft for limited preimplant augmentation procedures. J. Craniomaxillofac. Surg., 44(3):249-56, 2016.

Sakkas, A.; Wilde, F.; Heufelder, M.; Winter, K. \& Schramm, A. Autogenous bone grafts in oral implantology-is it still a "gold standard"? A consecutive review of 279 patients with 456 clinical procedures. Int. J. Implant Dent., 3(1):23, 2017

Streckbein, P.; Kähling, C.; Wilbrand, J. F.; Malik, C. Y.; Schaaf, H.; Howaldt, H. P. \& Streckbein, R. Horizontal alveolar ridge augmentation using autologous press fit bone cylinders and micro-lag-screw fixation: technical note and initial experience. J. Craniomaxillofac. Surg., 42(5):387-91, 2014

Velásquez, H.; Olate, S.; Díaz, C.; Navarro, P.; Borie, E. \& de Moraes, M. Quantitation of Mandibular Symphysis Bone as Source of Bone Grafting: Description in Class I and Class III Skeletal Conditions. J. Oral Implantol., 43(3):211-7, 2017.

Verdugo, F.; Simonian, K.; Raffaelli, L. \& D’Addona, A. Computer-aided design evaluation of harvestable mandibular bone volume: a clinical and tomographic human study. Clin. Implant Dent. Relat. Res., 16(3):348-55, 2014

Voss, J. O.; Dieke, T.; Doll, C.; Sachse, C.; Nelson, K.; Raguse, J. D. \& Nahles, S. Retrospective long-term analysis of bone level changes after horizontal alveolar crest reconstruction with autologous bone grafts harvested from the posterior region of the mandible. J. Periodontal Implant. Sci., 46(2):72-83, 2016.

\author{
Dirección para correspondencia \\ Prof. Sergio Olate \\ División de Cirugía Oral, Facial y Maxilofacial \\ Claro Solar 115, Of 414-A \\ Temuco \\ CHILE
}

Email: sergio.olate@ufrontera.cl

Recibido : 11-09-2017

Aceptado: 24-11-2017 